\title{
Robotics, Education, and Sustainable Development
}

\author{
M. Bernardine Dias and G. Ayorkor Mills-Tettey \\ Robotics Institute \\ Carnegie Mellon University \\ 5000 Forbes Ave., Pittsburgh, PA 15213, USA \\ \{mbdias,gertrude\}@ri.cmu.edu
}

\author{
Thrishantha Nanayakkara \\ Mechanical Engineering \\ University of Moratuwa \\ Katubedda, Moratuwa, Sri Lanka \\ thrish@elect.mrt.ac.lk
}

\begin{abstract}
The growing demand for technological innovation to enable empowerment of developing communities requires new and creative educational initiatives. Thus, well designed higher educational initiatives geared towards appropriate technology for developing communities can have a significant global impact. This paper presents the challenges and benefits of three higher education initiatives in Sri Lanka, Ghana, and the USA that focus on innovating and implementing relevant technology for developing communities. The authors examine the potential intersections of robotics and its component technologies with education and sustainable development. The paper concludes with an assessment of factors that contribute to the success of higher educational initiatives designed to enable technology relevant to developing communities.
\end{abstract}

\section{Index Terms - Education, Development, Robotics}

\section{INTRODUCTION}

The growing demand for technological innovation to enable empowerment of developing communities requires new and creative educational initiatives. Thus, well designed higher educational initiatives geared towards appropriate technology for developing communities can have a significant global impact. This paper presents some of the challenges and benefits of three higher education initiatives in Sri Lanka, Ghana, and the USA that focus on innovating and implementing relevant computing technology for developing communities. The motivation for this paper is presented next, followed by a description of the three case studies. The challenges and benefits of these initiatives are examined in the next section followed by a discussion of necessary elements for success when designing such initiatives. The paper concludes with overall recommendations and future directions.

\section{Motivation}

The United Nations (UN) reports almost half of the world's population lives on less than \$2 a day. Another billion people join them at the bottom of the economic pyramid forming a poverty base of 4 billion people (two thirds of the global population). But what exactly is poverty? The World Bank's PovertyNet program [5] defines poverty as:

Poverty is hunger. Poverty is lack of shelter. Poverty is being sick and not being able to see a doctor. Poverty is not having access to school and not knowing how to read. Poverty is not having a job, is fear for the future, living one day at a time. Poverty is losing a child to illness brought about by unclean water. Poverty is powerlessness, lack of representation and freedom.

While most of the poor require food and other basic necessities in the short term, a sustainable long-term solution to global poverty must involve empowerment of the poor to feed themselves and make their own livelihoods. Thus, sustainable development, that is, development that allows current generations to satisfy basic needs without depriving future generations of the same, is at the heart of the global agenda. In fact, eradication of extreme global poverty was the focus of the UN Millennium summit during which the world pledged to halve extreme poverty in the world by 2015 [7]. This is a goliath task that cannot be achieved by only a few. In a more proactive definition of poverty the World Bank's PovertyNet program [5] states:

\footnotetext{
.. Poverty is a call to action - for the poor and the wealthy alike a call to change the world so that many more may have enough to eat, adequate shelter, access to education and health, protection from violence, and a voice in what happens in their communities.
}

Thus, eradication of poverty will require a concerted global effort; it cannot be accomplished by the actions of a few.

Traditionally, most people support and rely on charitable organizations to address poverty. However, it is increasingly evident that charity alone will not eradicate poverty; instead, a drastic change in how we view poverty and the poor is necessary. In the words of author C. K. Prahalad [1], "If we stop thinking of the poor as victims or as a burden and start recognizing them as resilient and creative entrepreneurs and value-conscious consumers, a whole new world of opportunity will open up." A growing population of researchers, academicians, entrepreneurs, and multi-national corporations are recognizing the value, strength, and creativity of the population at the bottom of the economic pyramid and joining forces to battle global poverty in new and creative ways. Popular business models and products cannot be directly transferred to developing communities; instead appropriate business models and relevant products must be developed. The key to a sustainable program is empowerment of the people in the developing communities such that they are partners in the design and implementation of these programs. Appropriately designed educational initiatives must play a crucial role in this empowerment.

While most wonder how this topic concerns the field of robotics and computing, an increasing number of people are lobbying for innovative technology as a necessary tool for the empowerment of developing communities. In his flagship address at the Millennium Summit of September 2000, the UN Secretary General Kofi Annan made a declaration encompassing the whole scope of the UN's work and its future direction. This Millennium Declaration enunciates eight international development goals [7] which set the agenda for development-oriented Information and Communication Technology (ICT) initiatives conducted 
under UN auspices and led to the establishment of the UN ICT Task Force who reported, "the power of ICT can be harnessed to contribute substantially to realizing all of the goals in the Millennium Declaration either directly or indirectly." Moreover, one of the pioneers in Robotics and Artificial Intelligence (AI), Professor Raj Reddy, in his 1988 AAAI presidential address [6], urged AI and Robotics researchers to consider the challenges of the poor in technology research, and highlighted the necessity for innovative technology that will benefit the poor.

Inspired by the vision set forth by pioneers such as Professor Reddy and by the current demand for advanced technology relevant to developing communities, this paper focuses on the topic of advanced technology for developing communities, and the role of higher education in this area of study. The paper explores directions in which research and education in robotics and other advanced technology fields can benefit developing communities around the world, and help achieve the Millennium Development Goals.

\section{CASE STUDIES}

Several initiatives today are creating a strong intersection between technology and sustainable development in different ways. In this section we provide case studies of three specific initiatives, in Sri Lanka, Ghana, and the USA, that provide opportunities for higher education that address relevant technology for developing communities.

\section{A. Sri Lanka}

The University of Moratuwa in Sri Lanka is arguably the best technical university in the country. As a recent initiative, this university has embarked upon developing sustainable technologies for the humanitarian demining programs in the North and the East of Sri Lanka. This field of research is especially appropriate due to the recent cease fire after nearly twenty years of civil war in the country. It is estimated that Sri Lanka has around 2.5 million landmines in the Northern region which is less than $30,000 \mathrm{~km}^{2}$. Clearing these highly contaminated farmlands will take at least another ten years if it is done with manual labor using current technology [8]. Thus, the major challenge in a humanitarian demining program is to find technologies that can accelerate the progress of clearing dangerous unexploded ordinances out of civilian-occupied areas while ensuring the safety of the deminers and civilians. Thus, the university has undertaken to provide its faculty and students with opportunities to engage in research and development of technology solutions to this locally relevant problem. Detailed next are some of their research efforts on this topic.

Metal Detectors and Signal Classification: Currently available metal detectors are too expensive to be used in developing countries. Moreover, they result in many false positives because they cannot distinguish between metal pins in the landmines and other metal debris found in typical battlefields. Usually the false alarm rate varies between $99 \%$ and $99.9 \%$. This high rate of false positives forces deminers to frequently and unnecessarily dig to uncover harmless metallic objects. This has a two-fold harmful impact: first, the demining operations are drastically slowed down, and second, the deminers' focus is adversely affected. The University of Moratuwa has developed a novel metal detector based on very low frequency (VLF) transmission with an additional capability to classify different types of alloys. The classification algorithm uses technologies based on Wavelet transforms and Adaptive Resonance Theory [9] [10]. It can detect objects up to 5 inches under the ground. The cost of development is only 5000 Sri Lankan rupees (which translates to roughly 50 US dollars with current exchange rates).

Mobile Robot Platforms and Control Algorithms: A platform that can carry the metal detectors will speed up the process of landmine detection and improve safety significantly because it can remove the danger to the human operators. Such a robot has to be designed by taking several constraints into consideration. The most common antipersonnel mines in Sri Lanka are designed to detonate when a mass of $7 \mathrm{~kg}$ or greater applies pressure on them. Therefore, one challenge is to reduce the weight of all the robotic components if the robot is not meant to detonate the mines. The first robot designed is shown in Figure 1.

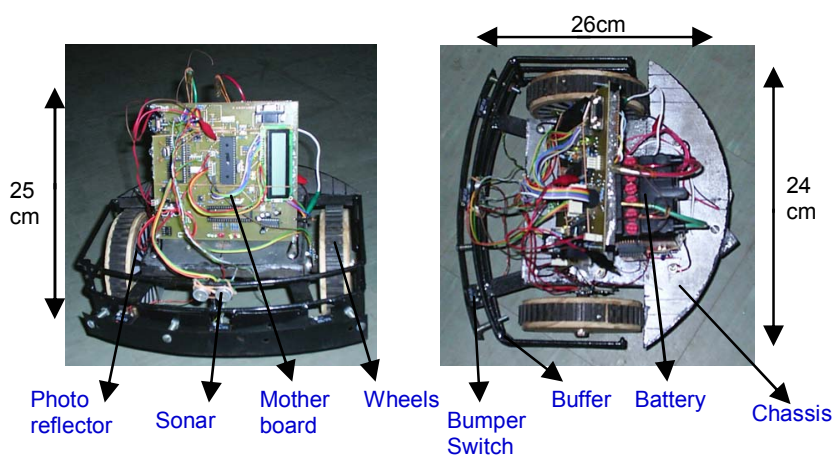

Figure 1: A low cost semi-autonomous robot

The robot is made out of wood with sonar and bumper switches to detect obstacles. Wheel speed is sensed by photo-reflectors. Interface programs and the control algorithms are written using the $\mathrm{C} 18$ language. Three PIC18F452 microcontrollers arranged in a network, using the SPI communication links, function as the brain of the robot. The USART port is used to communicate with a remote host for data logging and operator interface. This first robot was not sufficiently stable in the rough terrains of the minefields abundant with thorny bushes. Therefore, a second, legged robot was designed as shown in Figure 2.

Robotic Hands for Landmine Removal: A robotic hand to manipulate landmines can be useful if the force sensing and control can be implemented successfully. Some students undertook a study to examine the feasibility of designing such a robotic hand. The study showed that filtering and force control algorithms have to be simplified further before a fully embedded robotic arm can be realized.

These and similar projects benefit the students at the University of Moratuwa by engaging them in locallyrelevant research, and by providing them with opportunities to learn and explore innovations in robotics and related component technologies. 


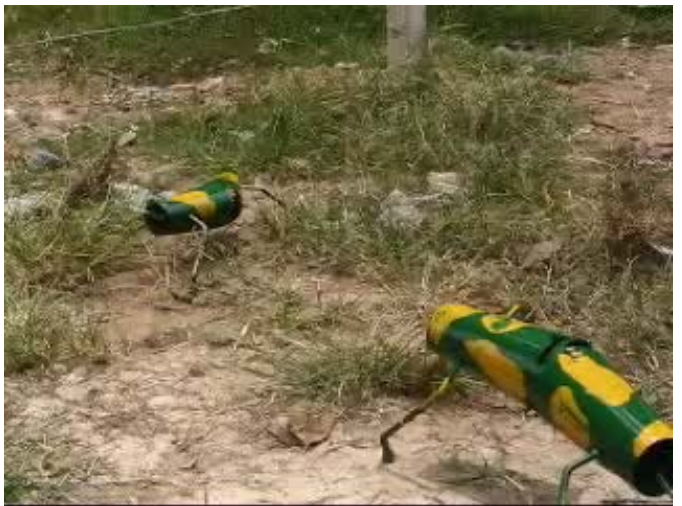

Figure 2: Legged robot that can walk freely on rough terrain and push a sledge to carry metal detectors

\section{B. Ghana}

An initiative in Ghana that clearly illustrates the beneficial impact of appropriate technology education in developing communities is Ashesi University. Ashesi University is a small liberal arts university in Accra, Ghana that began instruction in 2002. The university's goal is to "train a new generation of ethical and entrepreneurial leaders in Africa" [2], a vision which some might deem unattainable. Ashesi, however, has begun to attract public attention, both in Ghana, and in the United States [3][4]. The university has already made a great impact on its students, who in turn are beginning to make an impact on the wider community. Ashesi accomplishes this by encouraging critical thinking and problem-solving in its students, ensuring that students and faculty have access to state-of-the art computing facilities including access to numerous international electronic journals, and emphasizing project-based learning that constantly has students applying their education to the realities of the society in which they live. Among other means, this is done by getting students involved in projects with industry and other organizations in Ghana.

An example will serve to illustrate how technology-based education is empowering the students to create a positive impact in their community. Earlier this year, students participating in the undergraduate Human-Computer Interaction class collaborated with a non-governmental organization (NGO) to implement a data collection and management system for a health project in a remote rural part of Ghana. The NGO, "Project Concern International" (PCI), works in preserving mother-child health in remote areas of the Western Region of Ghana where there is a high infant mortality rate in part due to the long distance between villages and the nearest hospital. PCI trains communitybased agents (CBAs) from the villages to identify and treat common causes of infant mortality including dehydration and malaria, and to help mothers identify danger signs in their children early enough for them to get the children to the closest hospital. PCI asked the Ashesi students to help design and implement a database system that would enable them to keep track of the large amounts of data (currently recorded on paper) obtained from the CBAs. Managing and interpreting this information correctly would enable them to gain a better understanding of the health situation in the region and the impact of their work. It would also enable them to work more effectively with the government to achieve the United Nations Millennium Development Goal of reducing, by two thirds, the mortality rate among children under five by 2015 .

The primary human-computer interaction challenge that the students had to consider in implementing their solution was the low computer literacy of the CBA supervisors. They also had to consider poor network connectivity due to noisy telephone lines, and frequent power outages. Employing a user-centered participatory design approach afforded the urban students the opportunity to become familiar with the realities of life in a rural part of the country. It also allowed the students to utilize their knowledge of the local language and culture to gain a better understanding of the needs of their users. The director of the NGO was so pleased with the prototype solution designed by the students that he plans to bring it to the attention of the Ministry of Health for their consideration in other projects. This example clearly indicates the ability of education and technology to empower young people to contribute to development in their community and also to address the urban-rural divide prevalent in most countries. The enhancement of the current computer science curriculum at Ashesi with courses in Robotics will result in new and creative ideas for the application of computing technologies in Ghana.

In the past few years, several new private universities have been established in Ghana. This is a promising step towards alleviating the challenges faced by the public university system and training critical thinkers and problem-solvers. Other developments that illustrate the growth in the use of information and communications technology by the general population in this developing country include the proliferation of internet cafes and the growth of mobile phone networks to cover almost all regions of the country. Technologies such as these, when appropriately made accessible to developing communities, can inspire many creative innovations in their use if the appropriate research and educational infrastructure can be implemented as well.

\section{United States of America}

Innovating technology relevant to developing communities must not however become the sole responsibility of developing communities; the developed world must play a crucial role in enabling such technology. A relevant case study in the USA is the TechBridgeWorld initiative recently launched at Carnegie Mellon University [11]. This initiative aims to build relevant infrastructure and provide research and educational opportunities in technology-related themes relevant to developing communities around the globe. The TechBridgeWorld initiative promotes two principal types of programs: on-campus opportunities to study topics relevant to the theme of technology for developing communities, and opportunities to engage in field-studies and implementations of relevant technology in developing communities.

On-campus activities include courses, seminars, and independent study opportunities. Field studies in developing communities require more infrastructure and contacts and hence require longer planning and implementation timeframes. Some relevant implemented activities are the "Technology and Development for Four Billion" (T\&D4B) graduate course, the "Technology Consulting in the 
Community" undergraduate course, the TechBridgeWorld seminar series, the Student Technology Exchange Program for undergraduate students, and the "V Unit" independent study option for graduate students.

The T\&D4B course is a special topics course offered through the robotics and software engineering departments to graduate students and advanced undergraduate students at Carnegie Mellon University. The course investigates meaningful ways of utilizing advanced computing and related technology for development relevant to the world's poorer 4 billion people. The instructors consider technology to be an enabler of development, and encourage the students to study the intersection of technology, policy, and the business case with an emphasis on sustainable solutions. The precursor to this course was the ICT4B (Information Communication Technology for Four Billion) class taught in 2003 with collaboration from University of California in Berkeley, using real-time videoconference technology to create a virtual classroom across the two campuses.

T\&D4B covers three broad areas relating to technology and development; the broad economic and social contexts of development, current applications of advanced technology for sustainable development, and current needs for advanced technology to promote sustainable development. The students engage in meaningful debates based on assigned readings of relevant topics, and complete an independent project. Student projects vary depending on student interests and available data. Past projects include topics ranging from the impact of technology on women in the sex trade in Russia, to necessary infrastructure to "wire" Africa based on a study of available road maps. Other projects include using smart meters to prevent electricity theft in India, examining the sustainability and impact of Intel Clubhouses and examining the uses of advanced technology for medical diagnosis in Haiti's Albert Schweitzer Hospital. Other topics looked at appropriate use of an automated reading tutor to improve English literacy in Ghana, and even a study on the applicability of wearable computing to combat the AIDS epidemic in Africa. Students in this class continue to be highly motivated and enthusiastic in class participation and implementation of their projects. Future versions of the class will include a class-wide project with an implementation phase.

"Technology Consulting in the Community" (TCinC) was first offered in the Spring of 1998. This course engages sophomore, junior and senior undergraduate students, primarily in computer science and information technology, as process consultants in community-based organizations. The students learn process consulting while providing valuable assistance to the community organization. The course is best characterized as a learning partnership in which each partner benefits. For their community experience, students are matched one-on-one to work with a community partner. The community partner is a leader in a community-based organization. As the name suggests, community-based organizations are nonprofit groups whose mission is to serve the needs of constituents in their immediate geographical area. Community organizations provide a rich diversity of working environments, programs, and constituencies. Our community partners have represented senior centers, youth programs, family support centers, YMCAs, Boys and Girls Clubs, public access computer centers in public housing communities, a micro business incubator, community centers, schools and a settlement house among others.

The partner in the organization is typically an executive director, a director of a program, or a director of a computer center. The student meets with the partner for 3 hours each week at the partner's location. The student's consulting goal is to increase the technical capacity of the partner to use, plan for, and manage technology. By focusing on the partner, the consultant works to expand the technical capacity of the partner's organization. Technical capacity is defined as the value of technology to the organization, which is realized by well functioning computing and networking systems and, just as importantly, by staff with the knowledge and practices to use them productively. Increasing technical capacity is linked directly to the organization's mission. The student consultant seeks effective ways for the partner to apply technology in order to accomplish the organization's mission.

Students also meet as a class once a week. The class teaches students to be consultants: first by clarifying what their role is and then by leading them through a process of investigating the community organization's current situation, analyzing their problems and opportunities, designing and negotiating a scope of work and a work plan, documenting evidence of increased capacity, and providing recommendations for sustaining the gains that have been made. The framework of the final consulting report guides each stage of the process. This report becomes a valuable resource to the community partner. At the end of the semester, the students and their community partners make a joint presentation at a mini-conference attended by other community leaders, civic leaders, foundation program officers, and university faculty.

The TechBridgeWorld seminar series seeks to bring relevant speakers to the Carnegie Mellon University campus and promote debate and interest among the campus community on the topic of technology relevant to developing communities. A special emphasis is placed on providing opportunities to speakers from developing communities. Finally, the STEP program [13] and the "V Unit" [14] are two new endeavors to provide undergraduate and graduate students with the opportunity to engage in independent studies that broaden their perspective of the impact of their research beyond the classroom and laboratory. In the STEP program, undergraduate students from Carnegie Mellon University are partnered with a student from a foreign reputed university in an exchange program, where the two students together design and carry out a project relevant to a developing community in the partner's country. In the $\mathrm{V}$ unit (here "V" stands for "vision") the goal of the program is to help graduate students to learn how to formulate a vision for the greater impact of their research. Academic credit earned through the $\mathrm{V}$ unit can count towards the student's degree requirements. This opportunity was well received by the students who have proposed a range of independent studies. Examples include designing grammars for 
automated language translation for low-density languages, creating low-cost robotics toys for autistic children, and designing a tool to help evaluate the best means of providing clean drinking water in rural India. As well as a study of the networking challenges of an early warning system for detection of tsunamis, and statistical methods to evaluate soil properties for agriculture in Colombia. All of the TechBridgeWorld programs have been embraced with great enthusiasm by the Carnegie Mellon University community.

\section{CHALLENGES AND BENEFITS}

Higher education initiatives in advanced technology for developing communities offer unique benefits and challenges. This section explores these challenges and benefits for the three case studies presented.

\section{A. Challenges in Sri Lanka}

Securing necessary funding is often considered to be the biggest hurdle for implementing technology education initiatives in a developing country like Sri Lanka. Though insufficient funds continue to be a major issue, the most formidable challenge is the lengthy time lag to promote the importance of investing in proactive research. Immediate results often get high priority while programs that project benefits in the long term are often considered less desirable. This highlights the importance of development-enabling policies in developing countries. National and communitylevel policies can hinder or enable educational initiatives and other developmental processes based on their design and relevance to the community's long-term needs. Thus, learning to design and implement enabling technology policies for developing communities requires much attention by the research and academic communities. Limited access to necessary resources for technology implementations is another major challenge. Many items from DC geared motors to the microcontrollers have to be imported after battling with much red-tape in the university structure. This causes long delays. Therefore, technologies based on standard designs cannot be sustained. Furthermore, any implementation that needs electrical energy has to take into account that only $60 \%$ of the human habitats have access to grid electricity. Therefore, PC based designs will find it very difficult to survive especially in rural communities. Fully embedded designs that consume less energy are more appropriate in these environments.

\section{B. Challenges in Ghana}

Some of the challenges faced when implementing technology-related initiatives in Ghana include the low literacy rate among the rural population, and the high costs of technology, such as good network connectivity. Any project that seeks to be sustainable must take these challenges into consideration. Some of the greatest needs which may be addressed by a sustainable program that includes the application of advanced technologies include literacy and education, healthcare, and economic empowerment. In many ways, projects promoting literacy and education may have the greatest impact, as they give people the tools to harness their creativity and generate innovative solutions to problems.

\section{Challenges in the United States of America}

As in developing countries, obtaining necessary funding for educational initiatives relevant to developing communities can be challenging in the US. However, the reasons for the challenge are often motivated by a lack of awareness relating to global benefits from such initiatives. Thus, enhancing this awareness is a critical need in developed communities. Along with this awareness, an important perspective to engender is that of recognizing value in developing communities. Thus, it becomes crucial to emphasize shared responsibilities, ownership, and benefits in global partnerships that address technology initiatives relevant to developing communities. Beyond the perceptual challenges, many infrastructural challenges become manifest when establishing educational and research partnerships across cultural and national boundaries. Language barriers, cultural perspectives and clashes, insurance policies, health and dietary concerns, currency and environmental concerns, political corruption and instability, and safety concerns are some of the major challenges in this arena. However, many global partnerships currently succeed despite these challenges. Hence, appropriate partnerships to share relevant experiences, contacts, and infrastructure can mitigate many of these challenges.

\section{Benefits}

The major benefit to be gained from initiatives that explore technology applicable to developing communities is the empowerment of members of these communities. This empowerment could be intellectual or related to skillacquisition, but is often also economic as successful business models related to these technologies emerge. An additional benefit is the narrowing of the urban-rural divided which is significant, even within developing countries. However, an important factor to consider is that the benefits are not limited to developing communities. Global partnerships between developing and developed communities to share information, knowledge, and expertise, and collaborate on technological innovations will benefit all parties involved. The added perspective and creativity enabled through facing new challenges and benefiting from new cultural perspectives is a tremendous asset. In fact, a recent polling of CEOs of top engineering companies resulted in the joint consensus that international perspective and experience is in increasingly high demand for many employment opportunities in technical fields around the globe. Indeed, many technology-related multinational corporations such as Hewlett Packard, Microsoft, and Intel are investing in research initiatives to create technological innovations that can be marketed in developing communities.

\section{DISCUSSION}

Designing higher educational initiatives enabling technological innovation for sustainable development is a new and largely uncharted region. Based on the initiatives outlined in this paper and the experiences of the authors, the following principles are important elements of success: 


\section{A. Participatory research and design}

People living in developing communities have a greater understanding of the needs of their communities. Participatory design couples these people with others who have the technical know-how to develop suitable technology. Such an approach results in a bottom-up solution that is often more sustainable than a top-down solution does.

\section{B. Empowerment, rather than aid}

The key to sustainable development is empowerment of the members of the community to meet their own development needs. As such, knowledge transfer is often more important than technology transfer.

\section{Shared, rather than individually owned resources}

A significant challenge in developing communities is the high cost of technology. More research needs to be done in methods of reducing the cost and energy consumption of such technology. As long as costs remain high, an approach that has worked to address the affordability and profitability of technology is a shared access model, rather than individual ownership.

\section{Local partnerships}

This reiterates the point that was raised under "participatory design", by emphasizing that people in or close to a developing community have a better understanding of its needs. However, in thinking about how to develop technology suitable to the needs of a developing community, the paradigm that technology must be in the hands of the individual members of the community should not be a limiting factor. Sometimes, a greater impact can be made by using technology to enhance the functioning of organizations that work with these communities, as in the example of PCI.

\section{E. Global partnerships}

While local partnerships are required for local relevance, global partnerships are required for enhancing perspective and sharing resources. The importance of global partnerships is emphasized by its selection as the eighth Millennium Development Goal. Several models are currently being pursued for relevant global partnerships in technology-related higher education. Two examples are the Technology Peace Corps [12] and STEP: Student Technology Exchange Program [13] currently under consideration at Carnegie Mellon University.

\section{F. Sustainability}

Initiatives enabling technological innovation and education for sustainable development are inherently interdisciplinary endeavors. Both the technical questions and the economic and social questions are equally challenging. Sustainability has many facets, including technical feasibility, economic feasibility, social and cultural relevance, and ownership. As more researchers, academicians and entrepreneurs enter this arena, many additional successful models will emerge.

\section{G. Evaluation metrics}

For purposes of funding and assessing academic merit, defining suitable evaluation metrics is crucial. This is not however a simple task. Many of these initiatives won't show measurable impact under conventional metrics for at least a decade. Hence, new metrics must be designed for evaluating shorter-term impact. A crucial metric for evaluating long-term impact will be the level of participation of developing communities in the innovation of technology.

\section{CONCLUSIONS AND FUTURE DIRECTIONS}

The growing demand for technological innovation to enable empowerment of developing communities requires new and creative educational initiatives. This paper presents some of the challenges and benefits of three such higher education initiatives, and a discussion of necessary elements for success when designing such initiatives. The next few years will yield first results from the described programs, and provide additional data for evaluating these initiatives. We hope this paper encourages the implementation of many more educational initiatives that address the important topic of technology relevant to developing communities.

\section{ACKNOWLEDGMENT}

The authors wish to acknowledge the support of Carnegie Mellon, University of Moratuwa, and Ashesi University. Special thanks are due to the executive board and advisory board members of the TechBridgeWorld initiative.

\section{REFERENCES}

[1] C.K. Prahalad, The Fortune at the Bottom of the Pyramid: Eradicating Poverty through Profits, $1^{\text {st }}$ Edition, PA: Wharton School Publishing, 2005.

[2] Ashesi University, www.ashesi.edu.gh

[3] B. Dudley, "Ghana native left Microsoft to sow seeds of African Ivy League", The Seattle Times, September 14, 2003.

[4] T. A. Tizon, "Ghanaian Sees Education as Key to Africa's Future", The Los Angeles Times, November 28, 2003.

[5] World Bank PovertyNet program, "What is poverty?", http://web.worldbank.org

[6] Raj Reddy, Foundations and Grand Challenges of Artificial Intelligence, 1988 AAAI Presidential Address, AI Magazine 9 (4): 921, 1988.

[7] United Nations Millennium Development Goals: http://www.un.org/millenniumgoals/

[8] Jan Cornelis, Hichem Sahli, Marc Acheroy and Yvan Baudoin (1996); Anti Personal Mines, a world wide problem. "Detection of abandoned land mines" 7-9 October 1996, Conference Publication No. 431

[9] Amara Graps, An Introduction to Wavelets, IEEE Computational Science and Engineering, Vol 2, Num 2, Summer 1995.

[10] Gail A. Carpenter and Stephen Grossberg (2002): Adaptive Resonance Theory, Handbook of Brain Theory and Neural Networks, Second Edition

[11] The TechBridgeWorld initiative, www.techbridgeworld.org

[12] The Technology Peace Corps, www.techbridgeworld.org/tpc

[13] STEP: Student Technology Exchange Program, www.techbridgeworld.org/step

[14] The V unit, www.cs.cmu.edu/ vunit 